AVANT, Vol. XI, No. 2

ISSN: 2082-6710 avant.edu.pl/en

DOI: 10.26913/avant.2020.02.16

OPEN

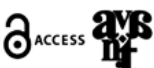

\title{
Writing as distributed sociomaterial practice - a case study
}

\author{
Aleksandra Koltun \\ Department of Philosophy \\ Maria Curie-Sklodowska University, Lublin, Poland \\ aleksandra.koltun@gmail.com
}

Received 25 November 2019; accepted 2 June 2020; published 21 September 2020

\begin{abstract}
Classical works on writing within cognitive science focus either on the aspects of written text production or the role of writing from a developmental and evolutionary perspective (Donald, 1991; Flower \& Hayes, 1981; Goody, 1977; Olson, 1996). Studies concerning the practices of writing in real-world settings are carried out within the framework of situated cognition (Klein \& Leacock, 2012; Menary, 2007; O'Hara et al., 2002), but they mainly focus on writer-writer or writer-artefact interactions. This paper provides an ethnographic account of writing that is understood as a practice that is distributed in a dynamically changing sociomaterial system. The cognitive task under study involves making decisions concerning the contents of a formal document as well as turning them into written text, both of which are supposed to take place in an informed and collaborative manner. Task performance depends on establishing a dense network of interactions that involves numerous sources of expert knowledge and people from various professional backgrounds who often represent clashing interests. The focus of the study is 1) identifying the resources employed in order to complete the task, 2) determining what functions they perform, 3 ) describing the ways that they are coordinated within the distributed cognitive system so that as a whole it creates incentives for some actions while constraining others. The analysis reveals how several resources contribute to realisation of cognitive operations while at the same time producing powerful effects upon the organisation of the cultural practices (Hutchins 2008) within the distributed cognitive system.
\end{abstract}

Keywords: writing; distributed cognition; sociomaterial practices; social dimension of writing; materiality of writing; external representations; cognitive artefacts 


\section{Introduction}

Writing has long been one of the focal areas of interest in cognitive sciences. Canonical psychological theories treat it as a problem-solving task in which a writer tries to achieve some kind of a rhetorical goal in a specific environment (cf. Flower \& Hayes, 1981). Writing involves three fundamental processes: ideas are generated and organised together with the goals (planning); the ideas are expressed in language then turned into written words (translating); finally, the text is read and examined to ensure that it meets the established goals (reviewing). Using one's own knowledge, which is stored in long-term memory, all these activities require the retrieval of information from the task environment, as well as constant interaction with the text.

Another large body of literature about writing emphasises its role in restructuring cognition. David Olson (1996) provides evidence for the thesis that learning to read and write is much more than acquiring the skill of translating sounds into speech. It consists in becoming aware of the very structure of language, which substantially changes the way we learn and think about the world. A more general claim comes from authors such as Jack Goody (1977) or Merlin Donald, (1991), who examine the role of writing and literacy in the rise of modern ways of thinking. These authors provide a range of arguments supporting the thesis that a shift made from orality to literacy fundamentally changes our cognitive capacities and the way we think and act.

The classical works on writing that have been mentioned focus either on the aspects of written text production or on the role of writing from a developmental and evolutionary perspective. Less attention has been paid to the actual practices of writing that take place in concrete sociomaterial settings. Some attempts of this kind have been made within the framework of situated cognition (Klein \& Leacock, 2012; Menary, 2007; O'Hara et al., 2002; see also Trybulec, 2013). They generally acknowledge the vital role that the environment and various external resources play in the subsequent stages of the writing process.

Nevertheless, even within situated cognition, the main focus of analysis is placed on interactions between two individuals or between an individual and an artefact or an external representation. Meanwhile, many real-world writing tasks involve close collaboration within large groups of people who employ various cultural tools concurrently. Such activities are often stretched across longer periods of time, requiring subtle coordination between social actors and subsequent versions of the text together with its material vehicles. And it is exactly the social dimension of writing, which is often mediated by numerous artefacts and external representations, that remains underexamined in cognitive sciences.

This paper aims to fill in this gap by providing a detailed account of writing understood as distributed sociomaterial practice. The argument is built on an extensive ethnographic casestudy research conducted in a Polish non-governmental organisation (NGO) dedicated to building civil society and improving the quality of public life. The task under examination consists in creating the contents of regulations for participatory budgeting in five Polish municipalities. As a mechanism for fostering public engagement, participatory budgeting has to be planned in a way that simultaneously ensures its feasibility and legitimacy. This means that the process of preparing the contents of regulations has to meet at least two basic requirements: 
firstly, several information sources are necessary in order to actually know what the procedure involves and how it can work in the local context; secondly, the whole process needs to be inclusive for various social actors, including experts, local authorities and civil servants, community members and NGOs. Therefore, the environment in which the task is performed has to be arranged in a way that fosters collaboration and an effective information flow.

Distributed cognition (cf. Hollan, Hutchins \& Kirsh, 2000; Hutchins, 1995) is applied as a conceptual framework that guides research questions and data analysis. The cognitive task under study consists in making decisions concerning the contents of a formal document as well as turning them into written text, both of which are supposed to take place in an informed and collaborative manner. Accordingly, successful task performance depends on three factors. Firstly, meeting participants should be eager to collaborate and thus share their internal knowledge. Next, what is shared has to stay relevant to the issues in question. Finally, the flow of information recalled from internal structures needs to be complemented with external sources, but only those which are adequate from the point of view of the established goals.

Various elements and resources are involved in task performance. There are meeting participants that bring their internal knowledge about the mechanism in question and the local conditions and demands. Also, the writing activities under study involve a range of cognitive artefacts and external representations, such as expert documents, printouts with examples of regulations or assignments, and paper sheets of varying sizes. It will be shown that both their contents and material properties perform certain functions for the realisation of a given cognitive task. Next, the way the environment is arranged promotes certain patterns of interactions between the meeting participants. Finally, the amount of time devoted to the realisation of a single subtask strongly influences the flow of information. Overall, the research conclusions address the question of how such elements and resources are employed and coordinated within a larger distributed cognitive system across time so that as a whole it provides for certain actions while putting effective constraints on others.

The following section of the paper outlines the main tenets of distributed cognition with a particular focus on studies that regard writing, understood both as a written text and an activity. Next, I describe the research setting and its methodology. Subsequent sections cover the key research findings, including an overview of the resources employed to achieve the goal of the cognitive task at hand, identification of their functions, as well as a description of the ways in which these resources are coordinated within a distributed cognitive system. The paper ends with a summary and conclusions, in which I address how various resources contribute to not only alleviating cognitive effort but also reorganising the cultural practices that are undertaken within the system.

\section{Writing from the distributed cognition perspective}

Distributed cognition is a framework that seeks to explain cognitive activities as occurring in interactions between people and their environment. It assumes that cognitive processes involve complex coordination at different time scales between internal resources (memory, attention, inference, etc.) and external resources (e.g. artefacts, dimensions of writing). Hollan, Hutchins, and Kirsh (2000, p. 176) list three dimensions of distributed cognition: 1) distribution in space 
- cognitive processes can be distributed across material and environmental structures; 2) distribution among a social group members; 3 ) distribution in time, which points to the fact that the outcomes of previous events can influence the course of future events.

Distributed cognition also takes account of cultural practices (cf. Hutchins, 2006, 2008). Culture is understood as "a process that, among other things, accumulates partial solutions to frequently encountered problems" (Hutchins, 2006, p. 379). According to Hutchins, for distributed cognition it is essential to look into the past experience of individuals and whole groups together with the trajectories of development of artefacts as they interact with the affordances that are available at the moment of task completion (Hutchins, 2006, p. 377). Importantly, he treats cultural practices as fully embodied skills related to particular ways of perceiving and acting in the world, not as disembodied representations of knowledge (Hutchins, 2008, p. 2012).

The environments in which people operate are treated as much more than a context for action, or even an external source of memory (cf. Hutchins, 1995; Kirsh, 1995). In distributed cognition, environments operate as dynamically changing landscapes which play an active role in the system's performance. On the one hand, they prompt agents to adapt their behaviours; on the other hand, they are being constantly remodelled according to the current needs and the course of the tasks.

Rather than individuals, distributed cognition takes systems as the basic unit of analysis. Systems can consist of individuals, elements of the natural and social environment, electronic media, artefacts, etc. The exact make-up of a distributed cognitive system at a given moment depends on the character of the cognitive task that is to be undertaken. A component is considered to be a part of the system on the condition that it performs some function with relation to the cognitive task at hand. As Kirsh explains, "The study of distributed cognition is very substantially the study of the variety and subtlety of coordination. One key question (...) is how the elements and components in a distributed system - people, tools, forms, equipment, maps and less obvious resources - can be coordinated well enough to allow the system to accomplish its tasks" (Kirsh, 2006, p. 258).

Distributed cognition is considered particularly suitable for analysing workflows in specific environments (Rogers \& Ellis, 1994). It has been applied in understanding various settings, ranging from large vessels (Hutchins, 1995a), airplane cockpits (Hutchins \& Palen, 1997), construction sites (Perry, 2017), railways (Andreasson et al., 2019), healthcare (Furniss \& Blandford, 2006; Nemeth et al., 2007) to an Elizabeth drama theatre (Trebble, 2011). As a theoretical lens, distributed cognition addresses complex patterns of collaboration and coordination in socio-technical systems, taking into account social variables, environmental features, and the effects they have on behaviour and performance. The application of ethnographic field research methods allows the dynamics of changes to be traced as they unfold naturally in real-life situations. Also, distributed cognition is considered to be a useful framework to support reasoning about system design and the impact of possible future designs on working practices and effectiveness (cf. Furniss \& Blandford, 2006; Hollan, Hutchins \& Kirsh, 2000; Kirsh, 2006; O’Hara et al., 2002). 
Writing activities have gained moderate attention in distributed cognition (cf. Klein \& Leacock, 2012; Menary, 2007; O’Hara et al., 2002). For instance, Richard Menary (2007) shows that creating and manipulating written sentences transforms our cognitive abilities. He adopts a conceptual framework called "cognitive integration". This is by no means synonymous with distributed cognition; however, his point of view is similar in that he analyses the cognitive task of writing in terms of "a co-ordinated interaction between neural processes, bodily processes and manipulating written sentences" (Menary, 2007, p. 621). Menary shows that a text is not only an output of neural processes, but also something that shapes the cycle of processing which constitutes the mental act. Written sentences are available for further manipulation that transforms the cognitive task. "The sentences extend my working memory and are, of course, what can be re-written, erased, moved to another paragraph, etc. It is, moreover, precisely these kinds of manipulations that are not easily, if ever, achieved in the head" (Menary, 2007, p. 629). Menary argues that it is possible to think of composing a paper without external media, but it would be much more difficult and written with different content and in a different style.

Klein and Leacock (2012) explicitly adopt the distributed cognition framework in order to show how external resources complement internal cognition in the process of writing (Klein \& Leacock, 2012, p. 136). They claim that "the knowledge that informs writing is a distributed, multi-layered system formed by external representations in the source texts and the writer's notes, as well as internal representations in the writer's long-term memory" (Klein \& Leacock, 2012, p. 139). They point to the fact that much cognitive research has been focused on writing activities that involve few external representations and only the writer him/herself. Yet, such situations are fairly uncommon. Many writing activities take place at workplaces where many people are involved in creating a single document, while the whole process is heavily supported by external representations and artefacts (e.g. source documents, computer software). This does not mean that no individual writing activity takes place in such contexts, but it is usually only a phase in a long-lasting process.

In their article, Klein and Leacock (2012) present an extensive review of studies that investigate the effect of using external representations and cognitive artefacts on writing activities. They show that there is a strong interdependence between such external resources and internal long-term memory, especially when it comes to the phase of planning the composition. For instance, research results indicate that the presence of an assignment increases the likelihood that the authors will start generating ideas immediately after reading it, rather than after other operations. Assignments also operate as scaffoldings for the goals, which affects text quality, both in terms of its contents and rhetoric. Next, source texts can be treated as an external source of long-term memory. They can instantiate extensive and detailed topic information, as well as facilitate constructive integration of contents from multiple sources. Also, there is evidence that spelling and transcribing words can be strongly distributed between internal representations and external computer software or human collaborators.

On the other hand, Klein and Leacock report that internal knowledge about composing a text has a greater effect on writing activities than distributed knowledge of analogous content. Also, research shows that producing coherent discourse appears to depend largely on the writer's internal abilities and not on external resources. 
Finally, O'Hara and co-authors (2002) offer a detailed account of writing activities that involve interactions between people, resources and artefacts available to them in the external world. They understand writing as a hybrid task in which one has to read, comprehend, synthesise and integrate information from multiple source documents while generating new compositions. Their article presents findings from a study of real-world situations in which a range of writers compose new texts while using several source materials (both in paper and onscreen) extensively.

The authors point to several kinds of interactions with artefacts while completing writing tasks, as well as the ways in which these interactions influence cognitive processes. They convincingly show how the material properties and contents of paper documents, such as books, printouts, loose copies, handwritten notes, encourage some actions while constraining others. For instance, a paper sheet allows information from various sources to be combined fairly effectively without much disruption to the workflow. It provides several visual reference points, such as page boundaries, and a specific layout that cues remembering and recall of information. The study shows that information found in paper documents often facilitated noticing and evoking knowledge that was in the writer's head but remained temporarily inaccessible.

Also, paper documents allow physical manipulation that supports attention (e.g. when placing a finger on the text, pointing to specific information, and turning your head to the screen), information search and integration (e.g. when rearranging the spatial layout of documents in order to compare and contrast effectively); they also provide scaffolding for the structure of the task (a particular organisation of documents can signal the accomplishment of an activity).

Finally, paper encourages taking personal, tacit and informal annotations - an activity which barely interrupts the ongoing cognitive task. Furthermore, the presence of annotations reduces the perceptual complexity of the source material by distinguishing certain points among less important information; it also might indicate that a more extensive source text is relevant (O'Hara et al., 2002. pp. 288-289).

On the other hand, O'Hara and co-authors indicate that electronic documents are used mainly as a source of quotes or other specific information to be combined with the emergent composition. They are rarely used for less-guided searches or the generation of ideas.

All in all, the key point of the articles presented above is that activities related to writing consist in producing external representations that serve as an input to the processes which follow, such as integrating information from notes or refining a composition. Also, these articles account for the environmental context as crucial to understanding the writing practices. The spatial layout of source texts, printouts, annotations, etc. provides a scaffolding for the structure of the task at hand and can be rearranged swiftly as the nature of the task changes in time. Thus, the role in performing the task of external representations and the environment is not merely cognitive offloading. We dynamically reconfigure these resources in order to facilitate information search and integration, support attention shifts, facilitate perception and coordinate it with short- and long-term memory (cf. Hollan, Hutchins \& Kirsh, 2000; Kirsh, 2010; O’Hara et al., 2002). 
At the same time, the focus of the research conducted so far has been on a fairly limited range of interactions that take place between a single writer and another individual (a reviewer, coauthor), or between an individual and various tools or external materials. One of the basic premises of distributed cognition, i.e. its social dimension, remains underexplored in the field of writing studies. In this paper, I present a case in which the distributed cognition perspective is applied to writing activities that are realised in a collaborative manner by a group of people that represent various professional backgrounds and often have clashing interests. Effective information flow and decision making depend on not only providing adequate sources of knowledge; they also depend on ensuring that people share and integrate information in a lively debate. Consequently, establishing a dense network of interactions between them is vital to performing the given task.

\section{Research setting and methodology}

The argument presented in this paper draws on an ethnographic study that provides insight into writing activities that take place in a complex socio-material system from a distributed cognition perspective.

The study took place in a series of meetings during which groups of experts, local citizens, and officials were working on the local version of participatory budgeting. Although there is no universally accepted formal procedure for participatory budgeting, there are some stages or rules that are broadly considered essential. Participatory budgeting should allow community members to discuss and identify the local issues and priorities, then to propose projects that address these issues and, finally, to decide which of the projects should be realised. The last stage of participatory budgeting often (but not necessarily) consists in voting, the outcome of which is binding for local authorities. Launching participatory budgeting requires formal acceptance from local councillors and the mayor.

The meetings under study were part of a larger project whose aim was to reinvigorate the local administration, NGOs, and citizens towards more active engagement in the process of participatory budgeting in their home cities (for an empirical account of knowledge sharing in other project activities, see Kołtun, 2017). The project was carried out by a Polish NGO - The Unit for Social Research and Innovation 'Shipyard' (subsequently referred to as Shipyard), which is already recognized for its dedication to fostering civic participation.

The meetings took place in selected Polish municipalities. Their ultimate aim was to create a formal document that describes the local mechanism of participatory budgeting and is ready to be officially proceeded by the local authorities. The mechanism had to support potentially conflicting demands. On the one hand, it was supposed to comply with an accepted standard defining what participatory budgeting is and how it should work. On the other hand, the local procedure needed to match the local conditions (e.g. the size of municipality, its territorial division, the size of the overall budget). Otherwise, the local mechanism either could not be called participatory budgeting or would be malfunctional from the point of view of the community. 
Accordingly, the regulation was supposed to be created in an informed but collaborative manner. Shipyard members hosted most of the meetings, providing practical support and expert knowledge on participatory budgeting. Importantly, they co-authored and published a document that delineated the hard-and-fast rules for the mechanism, which were adopted as guidelines for the whole project. At the same time, meetings were open to all people interested. Eventually, their participants represented a whole range of social backgrounds: local citizens, NGOs representatives, officials and authorities. This diverse social make-up was supposed to ensure that the budgeting was feasible on the local level. For instance, local residents are often aware of issues that remain unknown to officials or authorities, while the latter are acquainted with formal regulations and policies.

The whole process of preparing the regulations and launching the budgeting took from a few months to over a year. Each municipality worked at its own pace and separately from one another yet following a similar path. The opening meetings were devoted to the presentation of participatory budgeting standards. They also served the purpose of establishing the ground for further collaboration, including the aims, the formal status of the group, and the method of work.

Most of the writing activities took place after the opening meetings were over. In this part of the process, local teams discussed a number of pre-set issues related to participatory budgeting, then made decisions regarding each issue, and wrote the content of what was decided on flipchart-sized paper. At the end of the meetings, each group presented the outcomes of their work to other participants.

Once the groupwork was complete, Shipyard members integrated all notes into an electronic draft of the document. Everyone engaged in groupwork received it and had a chance to make final comments or amendments. When the local team and Shipyard members had settled on all the content of the text, it was passed on to the lawyers who worked for the local city hall. Their job was to make the document legally correct without introducing any changes to its substance. Finally, the city council was supposed to vote on the regulations.

The study presented in this paper focuses on the course of the meetings. The final stages of the process, which included preparing the final versions of the regulations and launching the budgeting, are beyond the scope of this article.

Overall, the research took two years. The processes of data gathering and analysis were informed by the concept of "sensibility for practice" (Sedlacko, 2017). I focused on what people actually did and the artefacts they interacted with (not only what they said they did and interacted with) in everyday, mundane settings. I also paid special attention to how events and activities unfolded in time, in "an open-ended process, full of uncertainties, and where stability and predictability are not a given but continually need to be produced" (Sedlacko, 2017, p. 55). Finally, in the course of the whole study I made an effort to maintain a highly reflexive stance towards my own research practices.

Research involved using several data-gathering techniques. Most of my data came from overt participant and non-participant observation during various working meetings of Shipyard members, as well as official project activities. I also conducted numerous in-depth and semistructured interviews with Shipyard members, and an extensive study of official documents, 
working papers, informal notes, etc., produced by Shipyard, its collaborators and project beneficiaries (e.g. municipalities, other NGOs). Moreover, on various occasions, I discussed preliminary research results with Shipyard members, which greatly contributed to refining the research questions and findings. Data analysis procedures were based on the constructivist grounded theory (cf. Charmaz, 2006), with distributed cognition as a theoretical lens, prompting research questions and influencing the construction of concepts through data analysis.

\section{Research questions and analytical framework}

The cognitive task under study consists in making decisions upon the content of a formal document, as well as turning them into written text, both of which are supposed to take place in an informed and collaborative manner. This involves searching for information and integrating it from both internal and external sources, exchanging ideas with other people using argumentation, making and discarding alternative scenarios, making decisions, and, finally, formulating the content of what has been decided and producing a text that is accessible to people from outside the working group (e.g. Shipyard members). All these activities are highly engaging for several cognitive processes, including perception, attention, short- and long-term memory, problem-solving, as well as imagination and reasoning.

There are numerous challenges to completing the task. The first is to make people willing to share their internal knowledge. This is not obvious when there are a lot of meeting participants who often do not know each other or are well aware that they represent conflicting interests. The second challenge is to avoid people sharing knowledge which is irrelevant to the process. This happens fairly often when residents meet with local officials and authorities and thus treat this as an opportunity to report all pressing issues that are out of scope. The third challenge is to guide the process of integrating information from internal and external sources so that the outcome is compliant with the adopted standard. Finally, the whole process needs to be attractive and technically feasible so that the make-up of meeting participants stays more or less identical over time.

The leading questions for the study presented in this paper pertain to ways that various resources are integrated within a distributed cognitive system and dynamically coordinated so that the system as a whole provides incentives for some actions while constraining others. The key issues that the study addresses are the following:

- What are the resources that allow an environment to be created in which 1) meeting participants are eager to share information that is relevant to the task, 2) participants manage to integrate information, arrive at concrete conclusions, and write them down in a timely manner?

- What are the functions and properties of these resources?

- How are these resources coordinated within a distributed cognitive system?

I pay special attention to identifying the three dimensions of distribution: in space (including artefacts, external representations and the way that various properties of the workspace are rearranged), among participants (with specific focus on the varieties of knowledge that diffe- 
rent people and Shipyard members bring in), and in time (both across the meetings and within individual assignments that require propagation and transformation of representations).

In order to answer the questions concerning the way in which the environment for writing practices is arranged, I have applied a conceptual framework offered by Kirsh (2001). He analyses office contexts as complex ecological systems that have an underlying structure that supports task-specific needs (Kirsh, 2001, p. 306). Office employees are suited to such a work context only when the structure is available to them to act appropriately (Kirsh, 2001, 310). Kirsh introduces three concepts that are applied in this paper: entry points, coordinating mechanisms, and activity landscapes. An entry point is "a structure or cue that represents an invitation to do something - to enter a new venue or information space" (Kirsh, 2001, p. 311). By selecting entry points, such as the way that tables are arranged or the availability of printouts and stationery, as in the case presented here, users gain metadata concerning the structure of the task to be performed. A coordinative mechanism should be understood as "an artefact, such as schedule or clock, or an environmental structure, such as the layout of papers to be signed, which helps a user manage the complexity of his task" (Kirsh, 2001, p. 305). People rely on these mechanisms to synchronize activity, carry out tasks and activities, and manage at-hand resources. As will be shown below, a to-do list and a flipchart-sized paper sheet are vital for integrating information from external sources and internal knowledge, as well as making final decisions in a timely manner. Finally, an activity landscape is defined as "part mental construct and part physical; it is the space users interactively construct out of the resources they find when trying to accomplish a task" (Kirsh, 2001, p. 305). In the case presented in this paper, activity landscapes are a major factor that shapes the behaviour and ecology of the venues in which writing practices take place.

\section{Results}

Although the opening meetings do not entail many writing activities, they are crucial for establishing the grounds for future work. Their key objectives are to convey all information related to the standard model of participatory budgeting and to lay out the principles for further collaboration. Consequently, at each opening meeting, Shipyard members deliver a PowerPoint presentation that delineates the hard and fast rules for the mechanism and provides examples of how the model works in real situations. Moreover, the participants receive a package of documents and publications that convey more details on the standard model and its real-life applications. These include "Standards for the Processes of Participatory Budgeting in Poland", which is a brief, attractive booklet that provides all crucial information on the mechanism. Importantly, the "Standards..." were co-authored and edited by Shipyard members together with a host of other experts representing NGOs, local governments and ministries, as well as academia. At the time when the project was carried out, no other publications of this kind were available in Polish.

The other objective of the opening meetings is to establish an agenda for further work. Discussing the principles of groupwork has often proved more controversial than deciding on the model of participatory budgeting to follow. In some municipalities, the opening meetings outnumbered those devoted to properly formulating the regulations. The difficulty of deciding the 
agenda results from the fact that it is still fairly rare for officials to work on an equal footing with people that do not have any experience in public policy management. They do not have much trust in each other's intentions or knowledgeability. Consequently, opening meetings serve the purpose of explicating and agreeing on the formal principles which concern the local team and its prerogatives. They are also essential, at least initially, for building rapport and mutual interest between all the parties engaged in the process.

In the case presented herein, completing the cognitive task depends on establishing a dense network of interactions among meeting participants as well as with external sources of knowledge. This is crucial for achieving an effective flow of relevant information that is later supposed to be integrated into the process of decision-making. In the next section, I provide a review of the resources employed in order to complete the cognitive task under study. These include a range of external representations and cognitive artefacts, as well as various properties of the environment. Then, I move on to describe how these resources are coordinated within a distributed cognitive system over time.

\subsection{Resources for fostering information flow and collaboration}

After the opening meeting, it is assumed that the internal knowledge of all the participants is aligned to an extent that allows a flow of relevant information and effective collaboration. When "participatory budgeting" is mentioned, it is believed that there is a common referent that is specified in "Standards...". At the same time, Shipyard members host most of the meetings at which writing activities take place and thus their expert knowledge becomes available for quick consultations. Moreover, they provide a number of other publications and printouts that complement "Standards...". These include summaries on how to run the critical stages of participatory budgeting, best practices from the municipalities that have already launched it, reviews of voting, promotion techniques, etc.

Other materials provided by Shipyard are supposed to guide the groupwork by providing a structure to the task. Crucially, there is a to-do list containing all the issues that need to be addressed in debate and then turned into written text. The document is actually an extended list of contents from "Standards...". In this case, it serves as an assignment for the group. Moreover, there is a variety of stationery available to all meeting participants that is usually scattered on the tables. Paper sheets of different sizes and shapes often act as reminders of a given task, but there are also scaffoldings for integrating information, making decisions, and turning them into text in a collaborative manner.

As mentioned above, once the opening meetings are over, people should have a fairly consistent internal image of what the groupwork will be like. And indeed, afterwards, there are almost no incidents in which someone tries to undermine these fundamentals. This, however, is not entirely a result of the successful internalisation of the rules, which are strange to most participants. Effective collaboration is largely due to the usage of coordinating mechanisms, as well as manipulation of various environmental properties.

During most meetings, a particular device is used which constantly reminds the participants of the basic rules of conduct, such as silencing phones or not interrupting while someone is 
speaking. This device is a flipchart tripod which presents the guidelines such that they are visible to participants most of the time. However, its effectiveness lies not only in its intersubjective accessibility, but also in the fact that it does the job in an impersonal and thus largely uncontroversial manner. Without it, the meeting hosts would need to take up the unpleasant burden of indicating the inappropriate behaviour themselves. This, in turn, could easily end up in a confrontation that seriously endangers the information flow.

Still, the very fundamentals of good collaboration are based on the participants' goodwill and embodied habits. These include willingly entering conversations and sharing ideas or adopting a friendly attitude towards certain people. Hence, coordinating people's collaboration depends on the arrangement of the environment rather than formulating explicit rules. Before each meeting, Shipyard members make sure which pieces of furniture and equipment are moveable. For instance, if a room is normally used for voting, the tables have to be reorganised into islets at which small groups of people can interact simultaneously. Next, the overall number of seats is crucial to determining the size of the subgroups at the meeting. Too few members in a group means that the information flow is restricted and not very productive. Too many people can hinder all communication. Finally, too many subgroups in a single room may generate distractive noise and movement.

The resources listed above (documents, paper materials and printouts, space arrangements) are used extensively in the course of completing the task. They perform several functions that often change over time. Importantly, these resources not only complement information that is missing from the internal knowledge of meeting participants. Together they create a specific cognitive ecology that encourages people to take up some actions while making others less comfortable or even impossible to carry out. The question of how the resources are coordinated within the distributed cognitive system are addressed in the following sections of this article.

\subsection{Arranging activity landscapes for information flow}

In what kind of environment do the meetings take place? What does this environment offer to the people involved?

The meetings are usually held in rooms used by local offices for conferences or formal proceedings. Such venues are designed for orderly debate during which people take turns with little spontaneity; they promote a highly structured information flow that is based on formal hierarchies. Some of the meeting participants work at these places on a daily basis and have already developed specific routines of behaviour. However, entering such venues may give a sense of discomfort or insecurity to other people. The kind of information flow that Shipyard strives for, which consists in dynamic and overlapping interactions with a lot of bodily movements, seems unlikely to emerge in such an environment.

Consequently, the workspace for writing practices needs to be rearranged so as to encourage certain types of conduct while making others less probable: for officials, an altered setting should prevent them following their daily routines; for regular citizens, it has to be more welcoming. The goal is to foster recall and sharing of internal representations while making others less probable to emerge. 
In the photos presented below, we can see how one room can be arranged for different purposes. The activity landscapes vary, depending on the goal and the method of work.

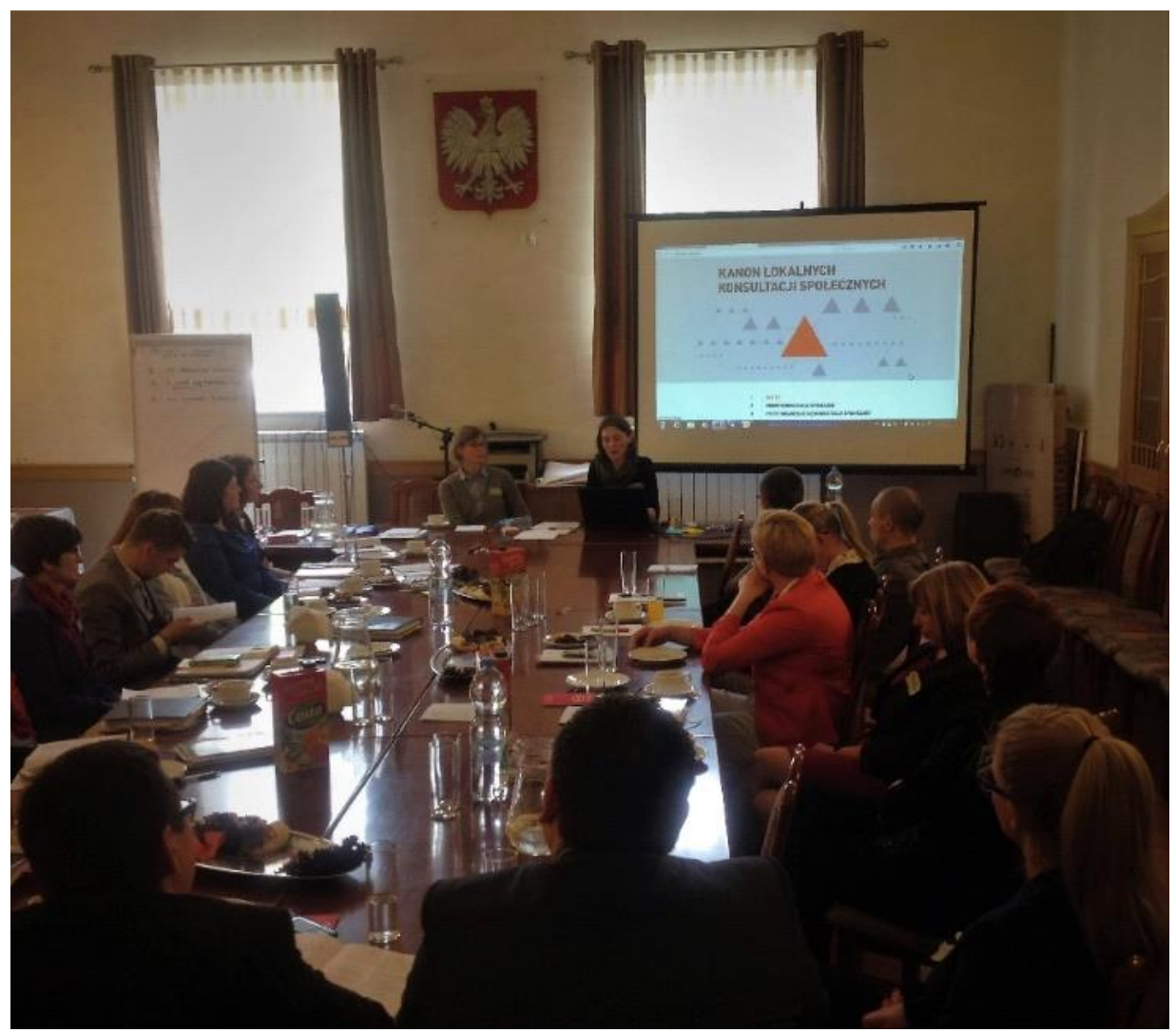

Figure 1. Activity landscape for a highly structured, linear information flow

In Figure 1, we can see a Power Point presentation on the screen; two presenters are commenting on its contents and a number of people are listening, all of whom are seated at a large table. The size of the table, its position in relation to the screen, the collocation of chairs, and the availability of stationery serve as entry points for the participants. Such an arrangement clearly indicates a lecture and suggests that it is essential that everyone gets familiar with and memorises the information conveyed - if not in the head, then by means of taking notes.

This kind of activity landscape is employed mainly during opening meetings. It reinforces a pattern of interaction that is characteristic of a structured and supervised information flow. Interactions are mostly one-way: from the presenters to the meeting participants. The people sit one in front of the other, therefore they can only see each others' backs. Due to the size of the table, those who sit face to face are too far apart to talk quietly. At the same time, there is a lot of stationery within easy reach. As a result, interactions with other group members prove 
much more difficult to carry out than interactions with the presenters, the screen, or one's own piece of paper. Although the participants are not directly facing the screen, they instinctively focus their attention on the presentation and the hosts. Alternatively, they can take notes, which means engaging in simultaneously processing the incoming information and creating external representations of it on paper.

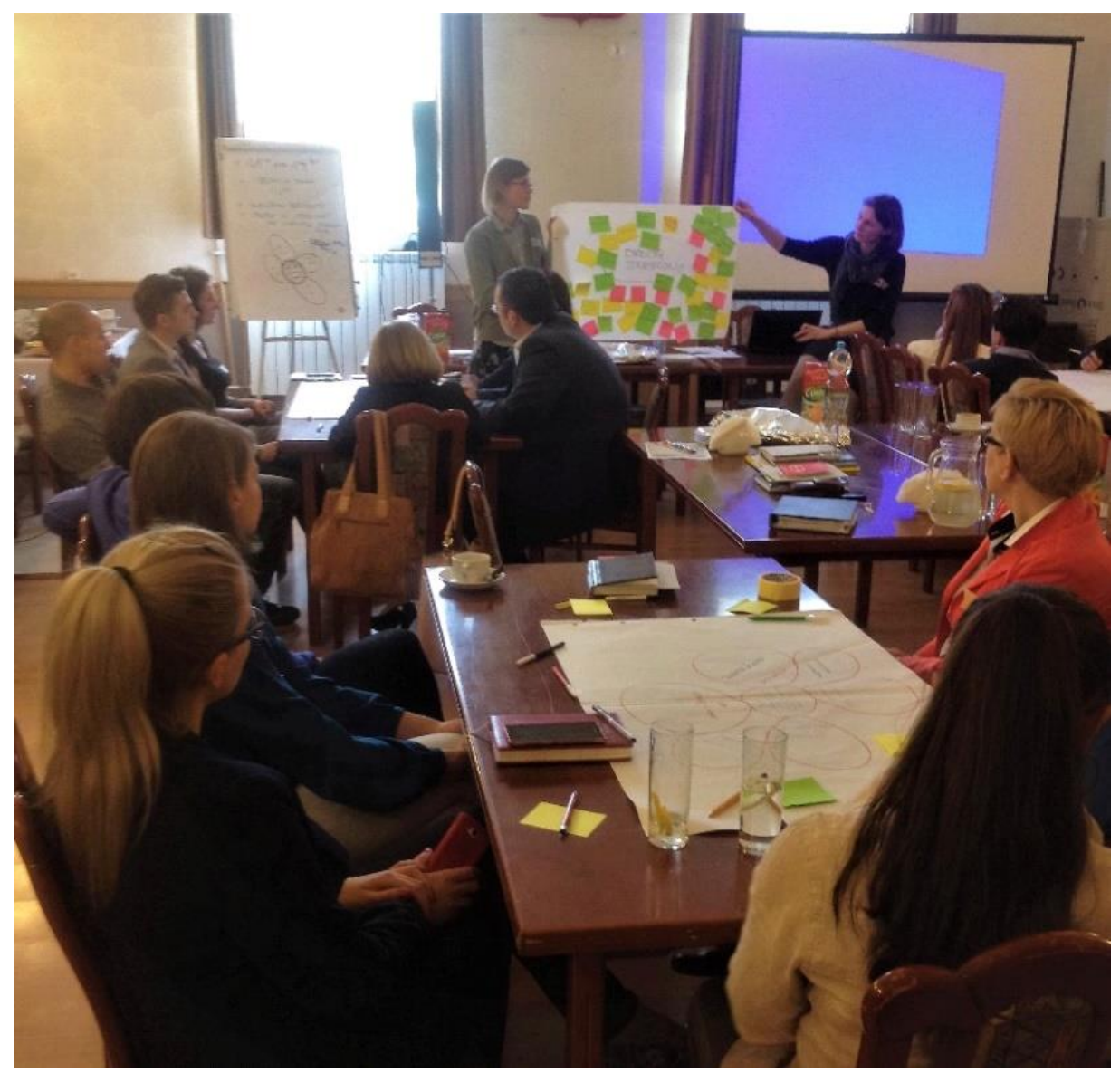

Figure 2. Activity landscape for an unrestricted, multidirectional information flow

Figure 2 shows the meeting hosts presenting the contents of a flipchart-sized paper sheet. They hold it in front of people seated in smaller groups. Each group has a separate table with stationery scattered around and a flipchart-sized paper filled with handwritten notes. The fact that there are several islets, the way they are arranged, as well as the availability of other supplies serve as entry points for the participants. They provide basic information on the nature of the activity to the subgroups, each of which is collectively creating some kind of a written outcome which is supposed to be presented to other participants. 
Most of the writing practices presented in this paper are organised in a similar activity landscape. Due to the size of the table, members of each group sit close to each other and are able to interact simultaneously and without much effort (e.g. changing body position or talking more loudly). Furthermore, the size of flipchart paper is a constant reminder of the fact that the activity's outcome should result from collective decisions (in contrast to writing ideas or questions for the presenters on an A4 sheet of paper, as in the activity landscape presented in Figure 1). Eventually, the space in front of all tables is temporarily turned into a stage for presenting the groupwork outcomes and a summary of the entire activity.

Information flow in this case is much denser than in the previous case. It involves a lot of spontaneous interaction, sharing of ideas, and an outcome written on paper. It is based on the meeting participants recalling internal knowledge. External representations are created collectively as a result of sharing and discussing the participants' internal knowledge. The purpose of creating external representations is not so much to aid memory but to make the outcome of the activity stable and intersubjectively accessible.

The ultimate goal of establishing the landscape for writing practices is to foster dynamic and multidirectional interactions that allow effective information sharing. Achieving this depends on providing numerous entry points that are metadata-rich and sufficiently intrusive, so that the meeting participants can make sense of them (cf. Kirsh, 2001, p. 315). The number and arrangement of tables and chairs suggest what the core activity consists in. Tables take most room space, while their arrangement and the materials placed on them provide information on the outcome of the incoming task. The variety of pens, markers and blank sheets of paper on the tables means that at least one task ends up with a written summary. Importantly, the size of paper sheets provides detailed information about the planned activities. The presence of post-it notes anticipates the generation of loose ideas or brainstorming. A4 or smaller paper suggests that everyone should take notes individually. Flipchart-sized paper means that some written summary will need to be shared with other participants. Finally, extra materials, such as publications or printouts clipped together, suggest that the task will require finding and integrating information from external sources.

\subsection{Managing information flow with external resources and time}

Shipyard members provide a variety of paper resources that are employed in the course of writing activities. All documents are left on the tables next to each seat, therefore everyone gets their own copy. This kind of arrangement, rather than piles from which individuals collect stationery for themselves, allows a variety of manipulations that support the realisation of the task.

The to-do list is one of the key resources used in meetings as a mechanism which coordinates information sharing during groupwork. The list shown in Figure 3 already has some annotations made by one of the Shipyard members. 


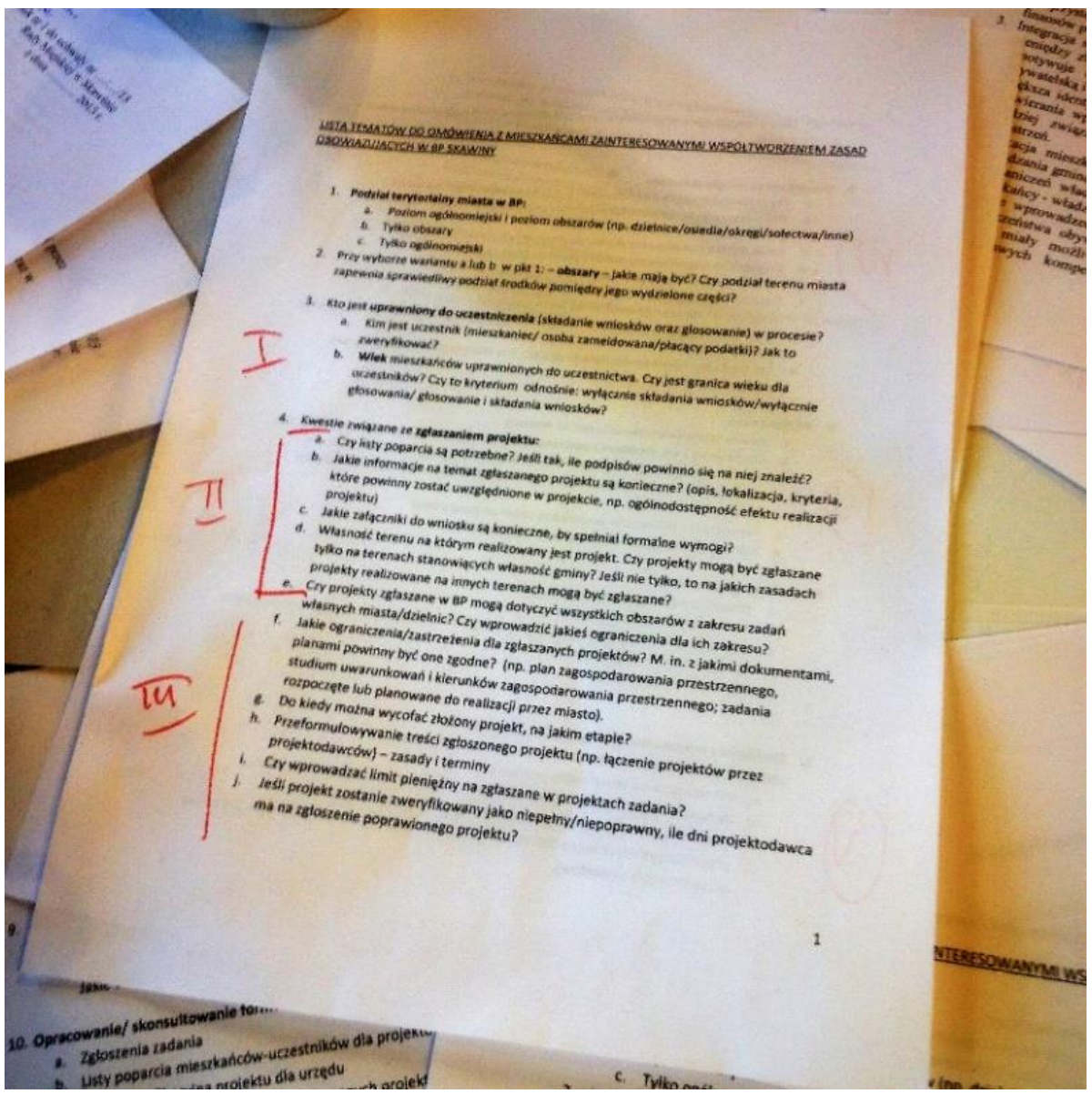

Figure 3. A to-do list as a mechanism that coordinates the sharing of relevant information from internal and external sources

The document contains a list of topics related to participatory budgeting that need to be discussed and decided upon by the meeting participants. It was created by Shipyard members on the basis of the "Standards..." content with the aim of aiding the supervision of various activities in the whole project. Its primary goal is to prevent some of the issues that are vital to participatory budgeting being overlooked. Thus, for Shipyard members, the list aids memory offloading. Throughout the process, however, the to-do list becomes one of the key mechanisms of completing more complex cognitive operations.

The to-do list is used for dividing the workload among the participants. A successful division consists in tying several factors together: the number of people participating, the amount of time available, and the expected outcome of a single meeting as compared to the pace of the whole process. The goal is to have an optimal number of subgroups so that they simultaneously work on the selection of topics and provide input to the regulations. 
The annotations made on the printout divide the contents of the document into parts, which are then numbered. Each digit will have a corresponding subgroup assigned to it to discuss the selected topics. The chunks are not identical in terms of the amount of bullet points included. At first sight, it seems that group I has a smaller workload than group II or III. Yet, the chunks are equal in terms of how much time for discussion they consume. Shipyard members are able to make such inferences based on their internal knowledge. They are well aware of what exactly each bullet point stands for in terms of the variety of issues and alternative scenarios that will have to be considered. Also, they have first-hand experience of which topics stir controversy and are therefore time-consuming. Consequently, the act of making annotations on the list is an externalisation of the outcome of a series of cognitive operations, including recall from long-term memory and a perceptually conducted assessment of the amount of information presented on a sheet of paper. Thanks to the list, the decisions concerning the workload division across time and among people become stable and stay visually accessible for further manipulations.

Next, based on the total number of the meeting participants and the size of the room, Shipyard members make an initial assessment of the number of subgroups. Once this is done, they turn their attention back to the list with annotations. The information which they are looking for is the number of chunks of bullet points, not their propositional content. Making this shortcut is possible thanks to the annotations made in the previous step. While the information about the number of chunks is visually available on the sheet of paper, Shipyard members are able to store information concerning the potential number of subgroups in short-term memory. At the same time, they contrast the two pieces of information against each other and, consequently, they can make a final decision on the number of subgroups, the size of chunks, and the amount of time assigned for the task.

The to-do list is also crucial for effective workload allocation to the subgroups. As mentioned previously, each meeting participant has their own copy of the document. Once they have been divided into subgroups, a Shipyard member comes to the fore and waves the list above their head, asking everyone to locate their copies. The next thing everyone does is look for the chunk of bullet points that they have been assigned with. They do not read the whole list. At this moment, no one is interested in the actual content of what they are searching for. The task consists in visually locating the right page and then the right range of bullet points. Usually, almost everyone locates their chunk, often marking it with a pen, and checks with other members of their subgroup for inconsistencies.

Without the list, the task of assigning the workload to each subgroup would pose a heavy burden not only on the participants' memory but also on sharing and processing information between them and Shipyard members. The paper document makes the content of the conveyed information intersubjectively accessible. As a material vehicle, it allows physical manipulation in space and via indexical gestures. In this way, it facilitates making attention shifts that do not disrupt the flow of actions. Finally, as a paper document, the list contains numerous visual cues, such as page numbers, page boundaries, and various text layout properties, which help to locate specific information without learning about its content (cf. O'Hara et al., 2002).

Finally, throughout the writing activities, a to-do list acts as a coordinative mechanism that binds people, internal and external knowledge, as well as time. It is shareable, so everyone is 
sure that they have the same knowledge of what the task consists in; it is stable across time, thus alleviating memory load. In the course of discussion, the list constantly reminds the members of each group of what kind of information they should be looking for. It fosters recall of internal representations that are relevant to the topic. Finally, it encourages complementing them with information from external sources.

At the same time, the list reduces the probability that a group goes off-topic. Some people cross out the bullet points on which they have already settled, creating an up-to-date picture of progress that is immediately available. Moreover, people constantly compare the amount of bullet points "to-do" to the amount of time left. The conclusion of such a comparison is usually that there is a lot of work and little time. As a result, most issues that are not directly related to the topic but still arise in discussion are postponed until a group is finished with the list. Such occasions turn out to be rare because Shipyard members carefully weigh the time given to complete the task against the amount of work.

The second kind of resources that are crucial to achieving the right information flow are publications and other expert materials provided by Shipyard and local offices. They complement the information that the meeting participants consider missing from their own knowledge, mainly with regard to the details of participatory budgeting. Also, they guide the recall of relevant knowledge concerning the local needs and conditions.

The information found in a document usually acts as an incentive for more interaction with both people and other materials. It triggers recall, encourages the participants to invent and evaluate alternative scenarios and solutions, and prompts them to find more detailed justifications for the decisions made. However, on some occasions printouts are treated as a source of ready-made solutions. This happens especially when meeting participants refer to examples of regulations in other municipalities. They tend to treat them as optimal for their own community because they are already operational and have been appraised by Shipyard. Thus, the documents constrain the recall of internal representations. Shipyard members try to identify such situations quickly and remind the group members that it is best to elaborate solutions that are context-specific and based on local expertise.

But what is it that causes paper documents and publications to be used so extensively throughout the process? After all, some meeting participants bring internet-connected laptops but eventually hardly use them.

Paper documents can be physically manipulated in a way that fosters information search and sharing. Groups divide the documents so that each person looks for certain information individually. Once everyone has finished this task, it is easy to share the outcomes by means of pointing to a concrete passage in the document which everyone has. Thanks to the properties of paper, sharing information in a group is a manual operation that is done with hands and eyes, not a complex procedure that requires recall and memorising.

Printouts can also be enriched with various annotations that facilitate combining information. People usually make notes next to the contents they are studying at a given moment. Sometimes, they externalise the information triggered from memory by writing it down next to their source. On other occasions, they jot down a number that represents a specific bullet point from the to-do list. Also, colours and capital letters are used consistently across several documents. 
All these operations provide visual cues that foster recall and integration of information across media. Annotations make the highlighted information or handwriting stand out from the rest of the content, which appears relatively homogenous. They also make stable connections between pieces of information from various sources, e.g. internal and external or several external ones (cf. O’Hara et al., 2002).

Figure 4 shows members of a subgroup using various documents. One person who is next to the woman in glasses is out of frame; only the paper she is holding is visible in the picture.

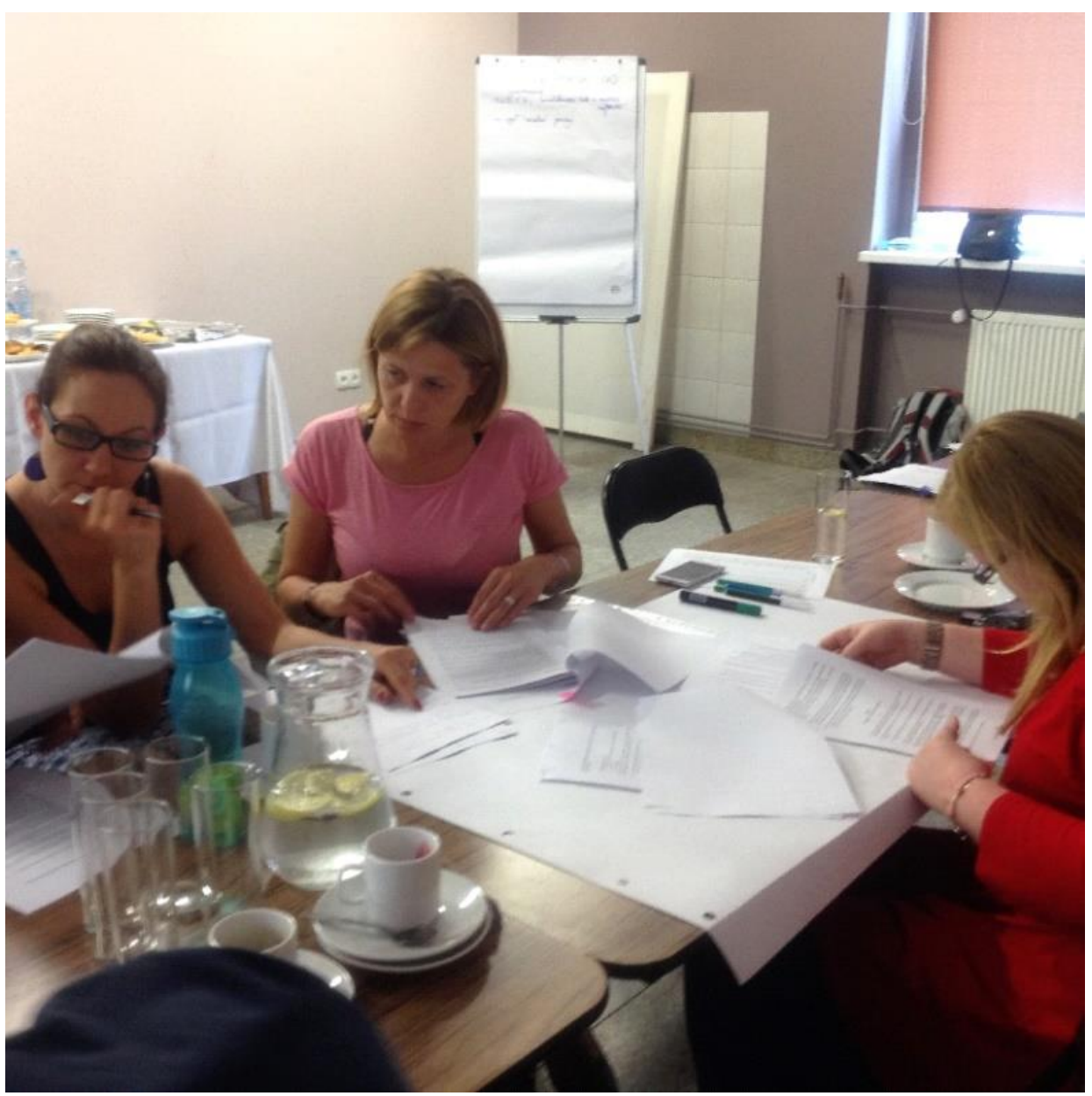

Figure 4. Using external sources for information sharing among group members 
The picture shows several activities taking place simultaneously over various printouts. First of all, the woman seated to the right is immersed in a search for some information and is not communicating with the other people. She is performing her task individually and independently of other members of the group because she has her own copy of the document. She occupies the only place on this side of the table and thus cannot be interrupted as easily as her colleagues.

Both women on the left look at the document held by the person seated outside of the picture. The look of their faces and their body positions (the hand with a pen next to the mouth, both hands performing the motion of turning the page, turning towards the person that holds the document of interest) suggest that they have been interrupted in the middle of another activity. Yet, now their attention is focused on the current task. The easiness of shifting attention from one document to another lies in the fact that this is an operation that is performed upon external representations in the world. On the one hand, people engaged in it can easily keep track of their previous activity by putting a finger on the place where they were interrupted. On the other hand, the interruption does not involve complex processing of orally conveyed information but rather looking at the part of the document indicated by the third person. All in all, the attention shift is founded upon perception and poses little threat of disrupting the workflow.

To sum up, the paper resources provided by Shipyard members foster the recall and sharing of internal knowledge and complement information that is unknown to the meeting participants. They act as an external source of information and a scaffolding for the structure of the task. Hence, they ensure that the shared and integrated information is rich yet relevant. Furthermore, paper resources can be treated as a means to control the course of task completion by actually narrowing down both the scope of the sources used and the topics raised. As for the former, paper documents have qualities that make their contents easy to identify, integrate, and share. This makes them much handier than, for instance, online sources, which may well contain information that is considered inappropriate from the point of view of the adopted model. Hence, when people find using the provided paper documents more convenient than their laptops, they actually ensure that the information they discuss stays appropriate. At the same time, the to-do list combined with a small amount of time allowed for task completion encourages the meeting participants to stay focused and reduce any issues that do not address the assigned topic directly.

\subsection{Flipchart-sized paper as a mechanism that coordinates information integration and de- cision-making}

The activities described so far have dealt mainly with information flow. They involve manipulating various resources without which it would be hard to imagine successful task completion. However, it is the last stage of groupwork that poses the heaviest cognitive load on the meeting participants because the only stable, external representation that this stage entails is the actual outcome of the whole activity, namely a written summary of the final decisions. There are a few "by-product" external representations that could facilitate the very process of integrating information and making decisions. Sometimes people take notes, but they use them individually as a memory aid and link between media, not necessarily as a resource for sharing information. 
Ultimately, it is the flipchart-sized sheet of paper that is placed on the table in front of all group members that plays the central role in the completion of the final stage of the meeting. At the beginning, when people are focused on searching for and sharing information, flipcharts are covered with printouts and stationery. By the end of the meeting they have been filled manually with the decisions the group has made. However, being a vehicle for information is only one function that flipcharts perform. Their material properties and the actions that they allow make them crucial for coordinating a variety of cognitive operations, including integrating information, making decisions, turning them into a propositional form, and, finally, sharing them with other people.

A flipchart-sized sheet of paper on the table looks like a single, blank space of considerable size that should be filled with some content. These properties make it so visually acute that it acts as a constant reminder to the meeting participants of what the outcome of the activity should be. At the same time, the flipchart paper is used by Shipyard members to assess the pace of work just by keeping track of the amount of text written down. There comes a moment when one of the hosts urges all groups to start taking notes. Establishing when this occurs depends on the visual availability of the outcomes produced by each group. Thus, the flipchart paper acts in a similar way for Shipyard as the to-do list did for the participants of the meeting.

The size of the flipchart paper allows large, legible handwriting so that the contents of decisions are intersubjectively accessible. This is important in several stages of the whole process. During group discussion, legible handwriting allows all group members to see and refer to the contents of their decisions at all times as they do not need to exchange anything between themselves and do not usually even need to rotate the sheet. In this way, all members of the group stay up to date and the load on their memory is smaller. Moreover, the written sentences allow manipulations that, as Menary indicated (2007), would otherwise be impossible. Namely, it is easier to find inconsistencies in a series of decisions when their contents have been stabilised in a visually accessible manner. Then, making refinements to the text usually requires crosschecking with information from an external source. Due to externalisation on a large piece of paper, this operation can be carried out by several group members at the same time.

Figure 5 illustrates the moment at which text production started but a lot of issues are still unresolved. The person on the left is presenting some arguments, presumably taking advantage of the contents of a digital file opened on a laptop. The person seated centrally is listening with a facial expression that gives the impression that he is actively engaged in processing the information and formulating counter arguments at the same time. One of the group members on the right has taken their glasses off, thus marking an interruption from their activity. The second person to the right is searching through "Standards...", having reached almost the middle of the book.

This kind of activity landscape provides various incentives for interactions with documents and other people. Meanwhile, the flipchart at the centre of the working surface constantly reminds the participants of the need to ultimately integrate the gathered information, make decisions, and turn them into written text. The text that has been already produced is visible to all group members. The flipchart itself is large enough to accommodate various printouts and publications that help refine what has been already written and make further decisions. 


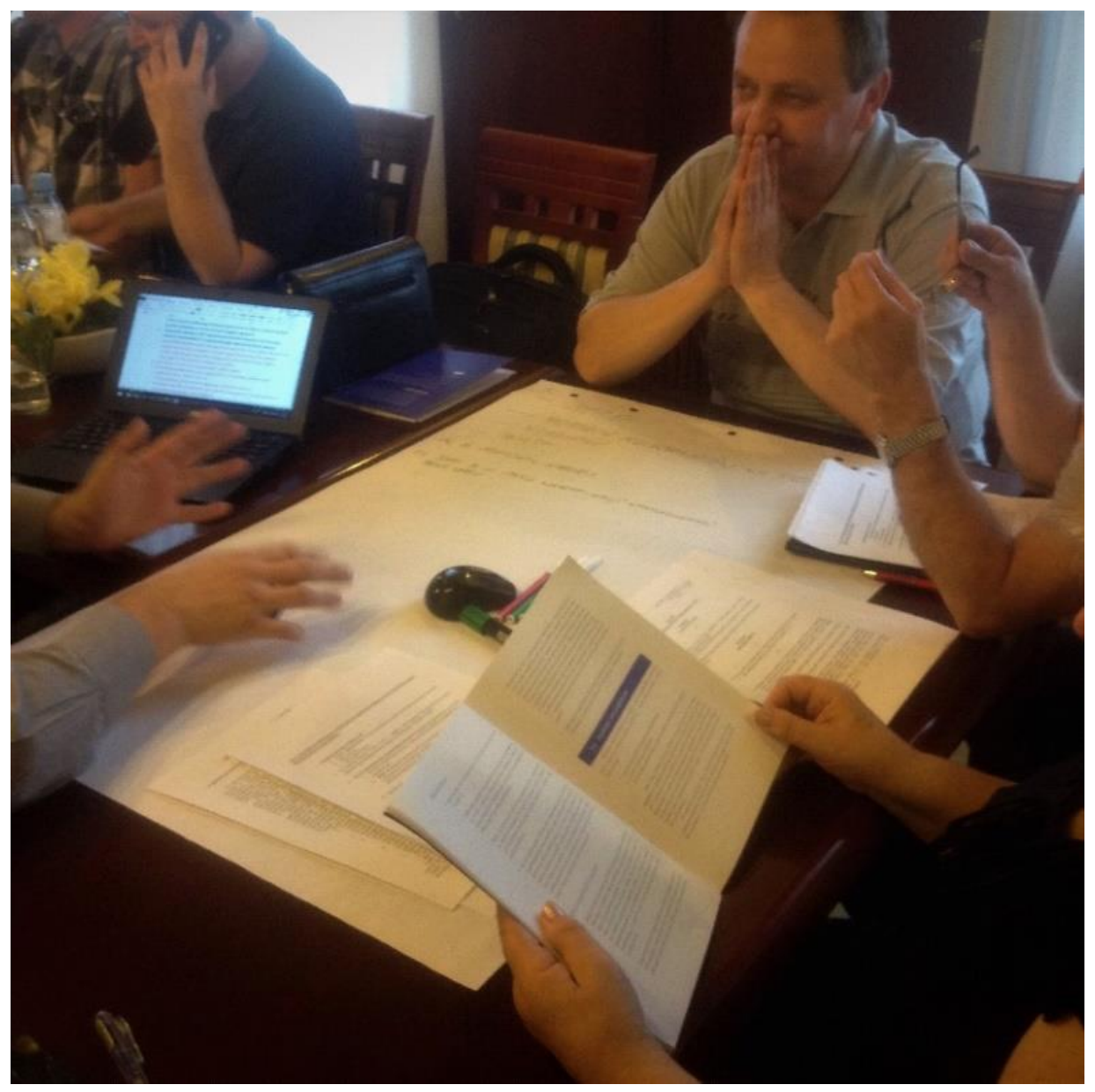

Figure 5. A flipchart-sized paper as a mechanism for coordinating integration of information and making decisions

The legibility of the text presented on flipcharts is also crucial for managing the information flow between the meetings. Flipcharts filled with notes are placed on the walls of the room on the following meetings; thus, they are the basis for addressing the differences between the internal representations of people that may have varying levels of experience in the process. Moreover, the flipchart contents need to be legible and structured in a way that allows them to be transferred to the final version of the regulations. The meeting participants do not copy the details of bullet points from the to-do list to the flipchart; they only write down the contents of their decisions. In this case, the to-do list serves as a coordinative mechanism again: the sequence of points in the flipchart reflects the sequence of the bullet points from the list, thus it refers to the issues that the decisions are supposed to address. Once all the meetings are over, 
Shipyard members are able to match the contents of notes on flipcharts to concrete components of the local participatory budgeting.

Figure 6 shows the exact moment of interaction between the writer, the flipchart paper, and the list. Importantly, the members of the group who are not engaged in producing the text are able to keep track of both what the writer is doing and the overall performance of the group. They are also engaged in searching for and sharing information to make further decisions.

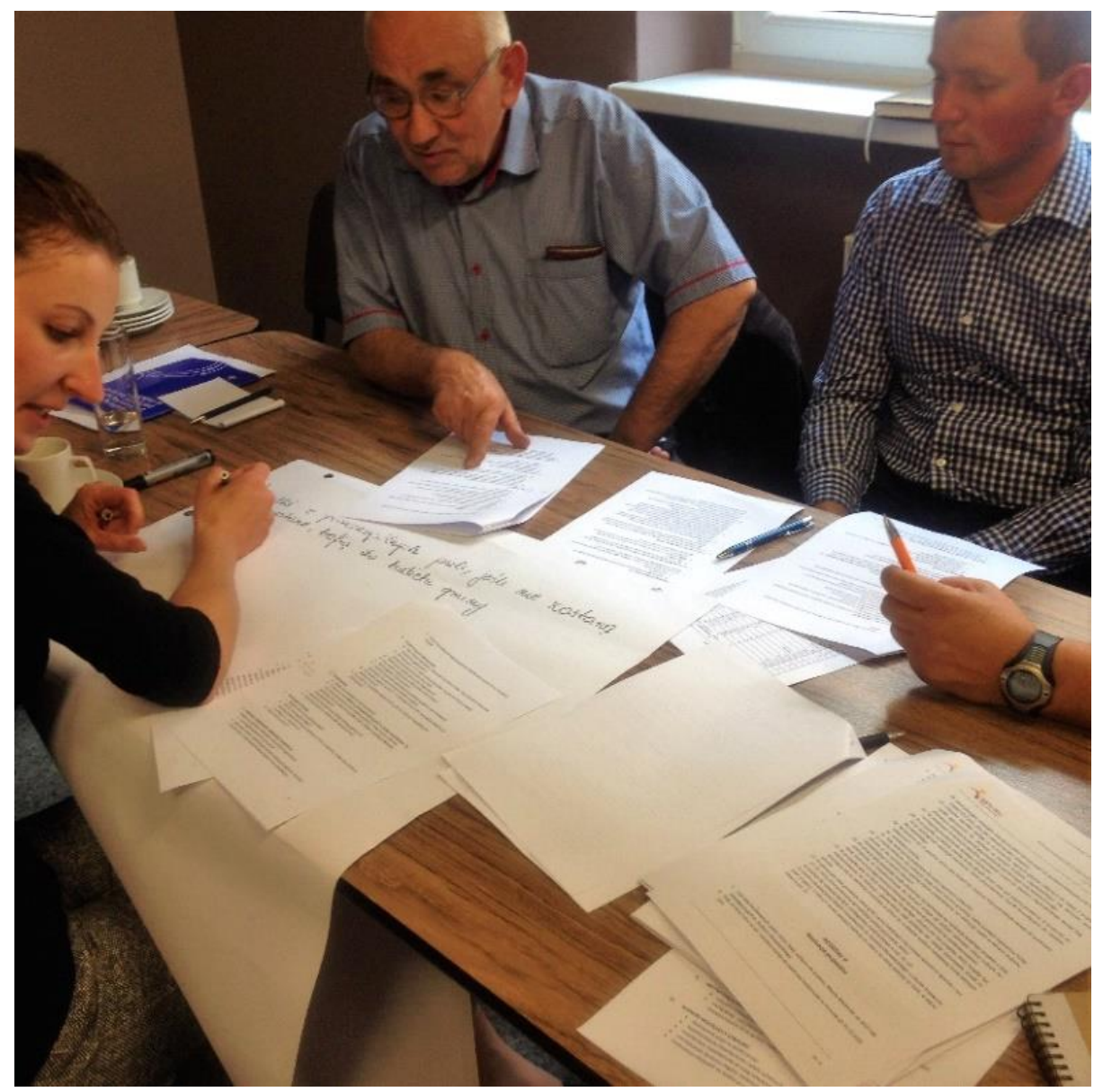

Figure 6. Coordination of text production by means of a flipchart paper and the to-do list

Importantly, flipcharts filled with handwriting reveal a lot about the course of writing activities as such. To a certain extent, they make it possible to determine which piece of information was added at which point in time. For example, one of the Shipyard members writes her notes about the "controversial issues" next to the main body of the text produced by a group. She does so in a smaller font, adding several question marks to each annotation; this makes it easy 
for anyone - not only the author - to identify the sequence of information processing and discern between the contents that have been accepted and those which require further debate.

Figure 6 is an example of what a flipchart paper usually looks like at the end of the writing activity. Note how well the contents of the flipchart paper depict the dynamics and hastiness of the processes of making and refining decisions. One can literally see the changes that have been introduced as the text was produced: thanks to the properties of paper and handwriting, all deletions and alterations stay visible.

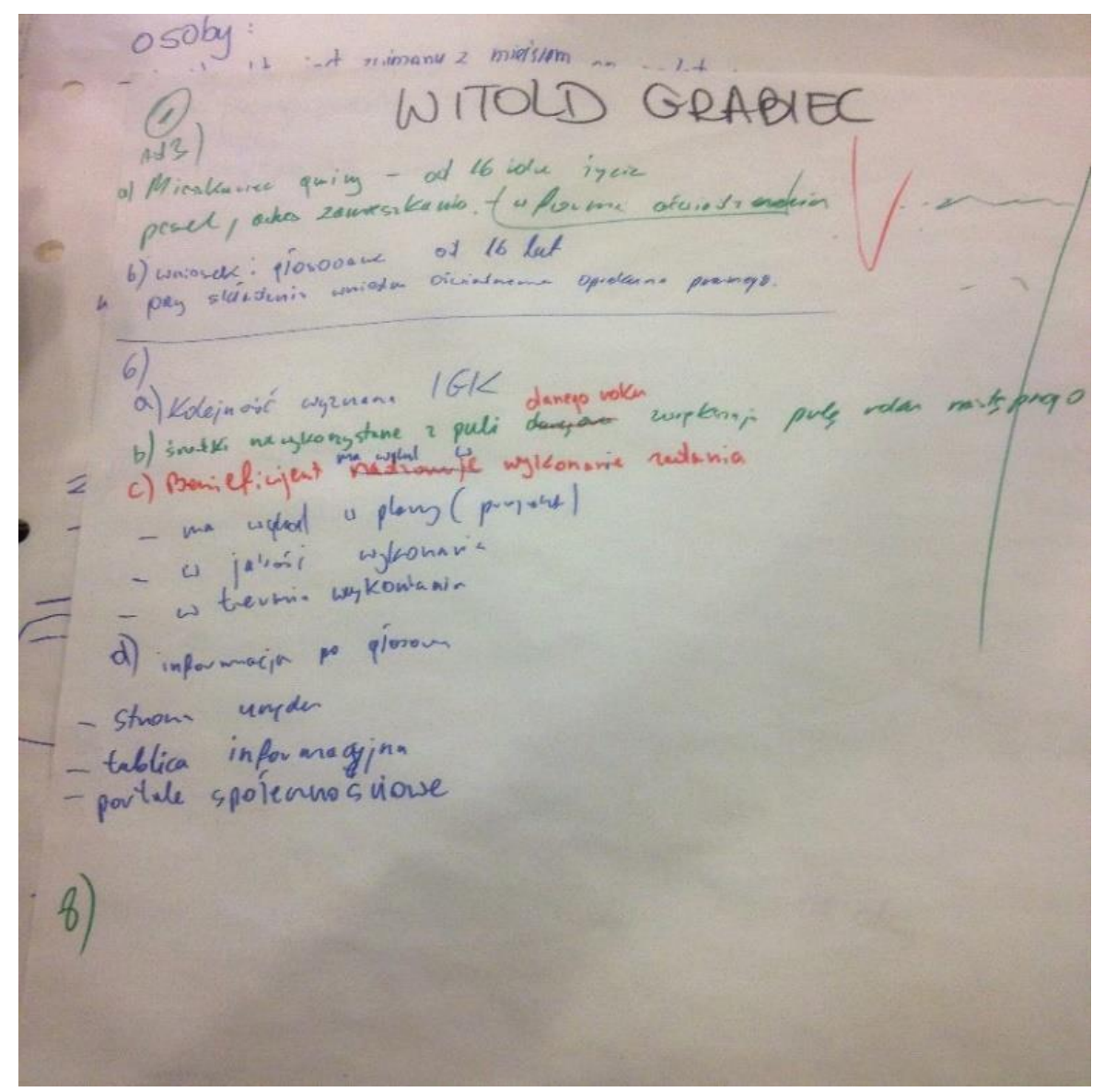

Figure 7. The outcome of the writing activity: a flipchart filled with notes representing the contents of the decisions made by a group

At the end of every meeting, each group places their flipchart on a tripod and presents its contents. This is the moment when information is integrated across groups, and this operation is managed mainly by Shipyard members. They are able to identify inconsistencies between decisions made by different groups and at different meetings. Also, the presentations provide 
an opportunity to give more detailed justifications for the decisions made. Extra information conveyed orally usually pertains to various options that have been ruled out and the reasons for doing do. Hence, the participants share information that is not central to their decisions but which was an important part the process.

All in all, the process of making decisions and composing a text on a flipchart-sized paper entails a continuous exchange and coordination of internal and external sources of information. Text production as such involves offloading memory and sharing its contents, not only among the group members but also with Shipyard representatives. It would be virtually impossible for a single person to remember the arrangements made by all groups in all meetings across various municipalities. In addition, as the whole process requires integration of internal knowledge regarding the local needs and conditions, it cannot be simply reconstructed from recall by Shipyard members. Finally, the fact that the text is placed on a flipchart-sized paper reveals the collaborative nature of the entire decision-making process.

\section{Summary and conclusions}

The overarching aim of the study presented in this paper is to provide an insight into writing understood as practice that is distributed in a dynamically changing sociomaterial system. The cognitive task under scrutiny involves making decisions on the contents of regulations for local participatory budgeting, as well as turning them into written text in an informed and collaborative way. Importantly, the people involved in this task are not tied by any formal relationship or hierarchy, but they often have clashing interests and come from different professional backgrounds. On the one hand, they are supposed to share their internal knowledge; on the other, they need to complement it with external sources of information. Therefore, establishing a network of dense, multidirectional, and spontaneous interactions among the people engaged as well as with several documents and publications is essential to all cognitive activities involved in task completion.

From a distributed cognition perspective, the unit of analysis comprises a dynamically changing, sociomaterial system that consists of people, activity landscapes, external representations, and cognitive artefacts.

People. The locals who participate in the meetings provide knowledge about the place where they live and its specific issues and demands. Importantly, their diverse backgrounds should allow information to be integrated from various perspectives that may be absent from the knowledge of any one individual. Their knowledge is usually highly context-specific and diverse; therefore, their recall from internal structures has to be guided so that information shared with other people is adequate from the point of view of the goals that have been set.

Shipyard members act as experts acquainted with the standard model of budgeting as well as its numerous versions, local solutions to specific problems, and the potential consequences of various decisions. Their knowledge is propositional (it is the knowledge "of" models, solutions, rules) as well as tacit and practice oriented (knowledge "how", addressing specific problems and limitations). However, the essence of their expertise lies in their ability to detect contradictions throughout all the groupwork. Inconsistencies happen fairly often because the process of decision making is extended in time and the participants of a meeting forget what 
was previously settled upon or simply fail to make connections between various pieces of information. Moreover, Shipyard members are capable of anticipating the future consequences of decisions made at a given moment. The participants cannot know the consequences of their decisions yet as they will only become apparent at subsequent stages of the process. But Shipyard members often present the consequences of alternative solutions from the point of view of the decisions that will have to be made in the future. Shipyard members' internal knowledge about participatory budgeting is both extensive in terms of informational content and wellintegrated in terms of the ability to combine information concerning seemingly separate aspects of the same issue. The experts retrieve and integrate information from long-term memory in a way that is unavailable to people who have less formal knowledge and practical experience.

Nevertheless, during meetings, there are always too few Shipyard members to cater for the needs of all subgroups, both in terms of providing relevant information and fostering its flow between participants. Even if that were possible, the adequate conduct of the meeting participants would remain highly dependent on their embodied habits and goodwill, both of which are largely tacit. Consequently, task performance requires employing and coordinating several resources that serve two purposes: firstly, they alleviate much of their cognitive effort and even make some cognitive operations feasible at all; secondly, the combination of resources encourages people to adapt their behaviours in an appropriate manner without the need to refer to any explicitly formulated rules.

Activity landscapes. Entry points, such as the arrangement of tables, piles of printouts placed on them, or blank flipchart papers spread in front of each group, provide rich metadata concerning what is expected from the participants. At the same time, how participants are seated in relation to each other and how the working surface is arranged encourages frequent interactions between them as well as with the available artefacts.

External representations and cognitive artefacts. The various paper documents, materials, and the meeting participants form a functional relationship based on dense interactions. They entail an effective flow of information in which internal representations are transformed and propagated, both in discussion with people and as externalisations made on various pieces of paper (cf. Sellberg \& Susi, 2014).

The publications and other documents provided by Shipyard perform numerous functions in information search and sharing. Firstly, they are an external source of information that complements the internal knowledge of the participants. Secondly, the publications contain only information which is relevant from the point of view of the whole process. Hence, the contents of the documents provide a scaffolding for the structure of the task. On the one hand, if the participants do not have any knowledge on a given topic or run out of their own ideas, the information found in a document is a starting point for further discussion. On the other hand, internal knowledge that the documents trigger is supposed to be related to the debated topic. At the same time, the availability of the documents leaves room for Shipyard members to exercise their expertise in a different way than just being a source of relevant information.

Both, the to-do list and the flipchart-sized paper support situation awareness. They act as constant reminders of what should be done and how much is yet to be done. As for the to-do list, 
it is an external representation of the assignment's structure. The list aids memory and directs the information flow: recalling from memory as well as searching through other documents, and further integration of both sources. Next, the writing of text on the flipchart-sized paper allows a transformation of representations that would be hard to achieve solely in speech or in internal structures. Due to the size of the text and its stability over time, the decisions can be refined and combined with the outcomes of other subgroups' work, as well as during subsequent meetings. Finally, both the to-do list and the flipchart paper serve as an indicator of groupwork progress over time, thus pressurising the meeting participants to stay focused only on those issues that are directly relevant to the task.

The fact that all meeting participants have an identical format of paper documents makes the synchronisation of information from various sources and between people fairly easy. Comparing their contents is a perceptual operation that is often aided with indexical gestures. Moreover, the paper itself facilitates switching attention between internal and external representations, and, as a result, integrating information from various sources and among several meeting participants. This is because paper documents allow annotations and offer several visual cues that guide remembering and recall. The material properties of paper documents ensure that information flows seamlessly and is propagated across several components of the system. Such coordination would be much harder to achieve if online sources or computers were used.

In sum, the cognitive effects described in this paper are achieved by means of a subtle coordination of numerous resources, taking advantage both of their contents and material properties. Each component plays a role within the whole system, but it becomes operational only in the context of its relation to other elements (cf. Hutchins 2006, p. 390). The resources employed, including external representations, artefacts, and the environmental properties, perform all the functions listed by Zhang and Patel (2006, p. 335; see also Zhang, 1997): they aid short-term and long-term memory, provide knowledge and skills which are not available in internal representations, provide information that can be directly perceived so that little effortful processing is needed to encode it, support perceptual operators that make inferences fairly simple, and change the sequence of actions performed, thus transforming the nature of the entire task.

Yet, the research results point to one more function of the resources employed: they are coordinated in a way that produces powerful effects upon the cultural practices undertaken within the whole distributed system (cf. Hutchins, 2006, 2008). The space arrangement affects the embodied routines of moving around and entering conversations, thus making them more informal and dynamic. Combining the to-do-list with a relatively short time interval acts as an effective constraint on debating topics that are out of scope but might be highly controversial. Flipchart-sized papers filled with handwriting are treated as a representation of the outcome of collective effort, thus they reassure all the people involved in task completion that their decisions cannot be easily discarded or questioned. None of these effects is of a cognitive nature in a straightforward sense, but in each case a specific kind of resource or combination thereof plays an important role in establishing effective information flow within the whole system. Ultimately, the reorganisation of cultural practices is one more crucial factor that contributes to creating an environment in which group members employ their past experiences as well as learn new patterns of interaction with each other and with external sources in order to complete the given cognitive task. 


\section{Acknowledgements}

I would like to thank all three anonymous reviewers and Marcin Trybulec, the co-editor of this issue, for their remarks that fundamentally contributed to the revision of this paper. I would also like to thank Shipyard members and the participants of the meetings described in this paper for participating in the study.

\section{References}

Andreasson, R., Jansson, A. A. \& Lindblom, J. (2019). The coordination between train traffic controllers and train drivers: a distributed cognition perspective on railway. Cognition, Technology \& Work 21, 417-443. https://doi.org/10.1007/s10111-018-0513-z

Charmaz, K. (2006). Constructing Grounded Theory: A Practical Guide through Qualitative Analysis. Thousand Oaks, CA: Sage.

Donald, M. (1991). Origins of the modern mind: Three stages in the evolution of culture and cognition. Cambridge, MA: Harvard University Press.

Flower, L., \& Hayes, J. R. (1981). A cognitive process theory of writing. College composition and communication, 32(4), 365-387. http://dx.doi.org/10.2307/356600

Furniss, D., \& Blandford, A. (2006). Understanding emergency medical dispatch in terms of distributed cognition: a case study. Ergonomics, 49(12-13), 1174-1203. https://doi.org/10.1080/00140130600612663

Goody, J. (1977). The domestication of the savage mind. Cambridge, UK: Cambridge University Press.

Hollan, J. D., Hutchins, E., \& Kirsh, D. (2000). Distributed cognition: Towards a new foundation for human-computer interaction research. ACM Transactions on Computer-Human Interaction, 7(2), 174-176. https://doi.org/10.1145/353485.353487

Hutchins, E. (1995a). Cognition in the wild. Cambridge, MA: MIT Press.

Hutchins, E. (1995b). How a cockpit remembers its speeds. Cognitive Science, 19, 265-288. https://doi.org/10.1016/0364-0213(95)90020-9

Hutchins, E., \& Palen, L. (1997). Constructing meaning from space, gesture, and speech. In L. B. Resnick, R. Säljö, C. Pontecorvo \& B. Burge (Eds.), Discourse, Tools and Reasoning. NATO ASI Series (Series F: Computer and Systems Sciences) (Vol. 160, pp. 23-40). Berlin, Heidelberg: Springer. https://doi.org/10.1007/978-3-662-03362-3_2

Hutchins, E. (2006). The Distributed Cognition Perspective on Human Interaction. In N. J. Enfield \& S. C. Levinson (Eds.), The Roots of Human Sociality: Culture, Cognition and Interaction (pp. 375-98). London: Berg.

Hutchins, E. (2008). The role of cultural practices in the emergence of modern human intelligence. Philosophical Transactions of the Royal Society, 363, 2011-2019. https://doi.org/10.1098/rstb.2008.0003

Kirsh, D. (1995). The intelligent use of space. Artificial Intelligence, 73, 31-68. https://doi.org/10.1016/0004-3702(94)00017-U 
Kirsh, D. (2001). The context of work. Human-Computer Interaction, 16.2-4, 305-322. https://doi.org/10.1207/S15327051HCI16234_12

Kirsh, D. (2006). Distributed cognition: A methodological note. Pragmatics \& Cognition, 14(2), 249-262. https://doi.org/10.1075/pc.14.2.06kir

Kirsh, D. (2010). Thinking with external representations. AI \& Society, 25(4), 441-454. https://doi.org/10.1007/s00146-010-0272-8

Klein, P. D., \& Leacock T. L. (2012). Distributed cognition as a framework for understanding writing. In V. W. Berninger (Ed.), Past, present, and future contributions of cognitive writing research to cognitive psychology (pp. 133-152). New York, London: Psychology Press. https://doi.org/10.4324/9780203805312

Kołtun, A. (2017). From a text to practice and back again. Making knowledge(s) work for participatory budgeting in Poland. Central European Journal of Public Policy, 11(1), 13-27. https://doi.org/10.1515/cejpp-2016-0029

Menary, R. (2007). Writing as thinking. Language sciences 29, 621-632. https://doi.org/10.1016/j.langsci.2007.01.005

Nemeth, C., O'Connor, M., Klock, P. A., \& Cook, R. (2006). Discovering healthcare cognition: The use of cognitive artifacts to reveal cognitive work. Organization Studies, 27(7), 1011-1035. https://doi.org/10.1177/0170840606065708

O'Hara, K., Taylor, A., Newman, W., \& Sellen, A. J. (2002). Understanding the materiality of writing from multiple sources. International Journal of Human-Computer Studies, 56(3), 269-305. https://doi.org/10.1006/ijhc.2001.0525

Olson, D. R. (1996). Towards a Psychology of Literacy: On the Relations Between Speech and Writing. Cognition, 60.1, 83-104.

Perry, M. (2013). Socially distributed cognition in loosely coupled systems. In S. J. Cowley \& F. Vallée-Tourangeau (Eds.), Cognition Beyond the Brain. Computation, Interactivity and Human Artifice (pp. 147-169). London, Heidelberg, New York, Dordrecht: Springer. https://doi.org/10.1007/978-3-319-49115-8

Rogers, Y. (1992). Coordinating Computer-Mediated Work. Computer Supported Cooperative Work, 1(4), 295-315. https://doi.org/10.1007/BF00754332

Rogers, Y., \& Ellis, J. (1994). Distributed cognition: an alternative framework for analysing and explaining collaborative working. Journal of Information Technology, 9(2), 119-128. https://doi.org/10.1057/jit.1994.12

Sedlacko, M. (2017). Conducting Ethnography with a Sensibility for Practice. In M. Jonas, B. Littig \& A. Wroblewski (Eds.), Methodological Reflections on Practice Oriented Theories (pp. 4760). Cham: Springer International Publishing. https://doi.org/10.1007/978-3-319-52897-7

Sellberg, C., \& Susi, T. (2014). Technostress in the office: a distributed cognition perspective on human-technology interaction. Cognition, Technology \& Work, 16(2), 187-201. https://doi.org/10.1007/s10111-013-0256-9.

Various convenors. (2013.) Standardy Procesów Budżetu Partycypacyjnego w Polsce [Standards for the Processes of Participatory Budgeting in Poland]. Warsaw: The Unit for Social Research 
and Innovation 'Shipyard'. Accessed 1 January 2016. http://stocznia.org.pl/publikacje/standardy-procesow-budzetu-partycypacyjnego-w-polsce/

Tribble, E. (2011). Cognition in the Globe: Attention and Memory in Shakespeare's Theatre. New York: Palgrave Macmillan. https://doi.org/10.1057/9780230118515

Trybulec, M. (2013). Bridging the gap between writing and cognition: Materiality of written vehicles reconsidered. Pragmatics \& Cognition, 21(3), 469-483. https://doi.org/10.1075/pc.21.3.03try

Zhang, J. (1997). The nature of external representations in problem solving. Cognitive Science, 21, 179-217. https://doi.org/10.1016/S0364-0213(99)80022-6

Zhang, J., \& Patel, V. L. (2006). Distributed cognition, representation, and affordance. Pragmatics \& Cognition, 14(2), 333-341. https://doi.org/10.1075/pc.14.2.12zha

Aleksandra Koltun, $\mathrm{PhD}$, a researcher at The Department of Philosophy, Maria CurieSklodowska University, Lublin, Poland. My scientific interests concern issues related to utility of knowledge. I investigate this topic from the point of view of philosophy and social sciences as well as design and conduct empirical research in order to complement the theoretical import. I have a vested interest in combining sophisticated theories and methodologies with hands-on empirical studies of real-life situations. I am an author to a book (Can Knowledge be [a] Performative? Performativity in the Studies of Science; Lublin 2015) and articles in cognitive sciences, sociology and philosophy.

The editorial and publishing process of this publication has been financed by the Ministry of Science and Higher Education from the funds for the dissemination of research (DUN) within the framework of publishing activity, contract no. 711/P-DUN/2019, period of implementation: the years 2019-2020. 